\title{
Association between R353Q polymorphism for coagulative factor VII and severity of coronary artery disease in Iranian population
}

Sara Cheraghi ${ }^{1}$, Shokoufeh Shajiee ${ }^{2}$, Mohammad Ali Boroumand ${ }^{2}$, Leila Pourgholi ${ }^{1}$, Shayan Ziaee ${ }^{1}$, Maryam Sotoudeh Anvari ${ }^{2}$, Arash Jalali ${ }^{3}$, Gholamreza Davoodi ${ }^{4}$, Mehrdad Sheikhvatan ${ }^{1}$

${ }^{1}$ Tehran Heart Center, Tehran University of Medical Sciences, Tehran, Iran ${ }^{2}$ Pathology, Tehran Heart Center, Tehran University of Medical Sciences, Tehran, Iran ${ }^{3}$ Biostatistician, Tehran Heart Center, Tehran University of Medical Sciences, Tehran, Iran ${ }^{4}$ Cardiology, Tehran Heart Center, Tehran University of Medical Sciences, Tehran, Iran

\begin{abstract}
Background: Recent research has supported the central role of coagulative factors in advancing atherosclerosis and causing coronary artery disease (CAD). The present study, for the first time, aimed to clarify the relationship between R353Q polymorphism for factor VII and the occurrence and severity of $C A D$ in a large sample of Iranian population.

Methods: Nine hundred and nineteen consecutive patients with suspected CAD, who candidated for coronary angiography in the Tehran Heart Center between January 2006 and March 2007, were examined. The number of diseased coronary vessels was determined, and the severity of CAD was assessed by the Gensini score. Genotyping was done via the PCR-RFLP method.

Results: The frequency of $Q$ and $R$ alleles was $74.1 \%$ and $25.9 \%$ in the patients with $C A D$ and $75.2 \%$ and $24.8 \%$ in those without $C A D$, with an insignificant difference $(p=0.625)$. The frequency of $Q$ allele in the patients with single-vessel, two-vessel, and three-vessel diseases was $72.8 \%, 71.5 \%$, and 76.4\%, respectively; the difference was also insignificant ( $p=0.379$ ). No relationship was observed between the distribution of the genotypes and the number of the involved coronary vessels. The average of the Gensini score was $43.39 \pm 46.18$ in the patients with QQ genotype, $38.87 \pm 42.89$ in those with $Q R$ genotype, and $55.61 \pm 53.80$ in the ones with $R R$ genotype, with the difference not constituting any statistical significance $(p=0.084)$. Conclusions: The results suggest no association between $R 353 Q$ polymorphism for factor VII and the presence or progression of CAD in the Iranian population. (Cardiol J 2013; 20, 5 : 533-538)
\end{abstract}

Key words: coronary artery disease, coagulation, factor VII, polymorphism

Address for correspondence: Mohammad Ali Boroumand, MD, Associate Professor, Pathology Department, Tehran Heart Center, North Karegar Street, Tehran 1411713138, Iran, tel: 0098 (21) 88029256, fax: 0098 (21) 88029256, e-mail: maboroumand@yahoo.com

Received: 02.01.2013 Accepted: 06.03.2013 


\section{Introduction}

Various mechanisms involved in the formation of thrombosis and regulation of coagulation have been identified to stabilize coronary atheromatous plaques. Recent research has supported the central role of coagulative factors in advancing atherosclerosis and causing coronary artery disease (CAD) [1-3]. In this regard, coagulation factor VII seems to have an essential role in the initiation and extension of coronary atherosclerosis $[4,5]$. In the coagulation pathway, the main responsibility of factor VII is the catalysis of factor X, which converts prothrombin to thrombin and is an integral part of fibrin formation and finalization of the coagulation process. In addition, after the appearance of a lesion on the vascular membrane, activated factor VII can initiate coagulation in association with the tissue factor, which is exposed in the vascular lumen and therefore facilitates the occurrence of thrombotic events. Finally and following misbalancing homeostasis, elevated levels of factor VII increase the risk of CAD and also increase the probability of the occurrence of myocardial infarction (MI) following plaque rupture [6]. Activation and regulation of factor VII is potentially affected by both genetic and environmental factors. It has been revealed that some polymorphisms in factor VII gene can lead to the up-regulation or down-regulation of this gene and thus change the activation of this factor, as well as its level. Recently, R353Q polymorphism of factor VII gene has been introduced as a probable triggering factor for an increased risk of familial MI $[7,8]$. However, the reported results are a matter of controversy. R353Q polymorphism in exon 8 involves a missense mutation at codon 353 of the gene, resulting in an arginine to glutamine substitution, which seems to result in a lower risk of $\mathrm{MI}$ in CAD patients. In a study by Girelli et al. [9], patients homozygous for the dominant allele had a $72 \%$ reduction in activated factor VII activity, and the adjusted odds ratio for the occurrence of MI among the patients with this allele was 0.47 . Nevertheless, despite some strong evidence on the protective role of $\mathrm{R} 353 \mathrm{Q}$ polymorphism, some studies have not been able to find any significant association between this polymorphism and ischemic events in CAD patients [10-13]. This may be due to the fact that the gene expression and its related polymorphisms can be also influenced by some strong environmental factors, as well as by the characteristics of the target population [14].

The present study, for the first time, sought to clarify the relationship between R353Q poly- morphism and the occurrence and severity of CAD in a large sample of Iranian population.

\section{Methods}

\section{Study population}

The present study was approved by the Research and Ethics Committee of the Tehran Heart Center. A total of 919 consecutive patients with suspected CAD, who were candidates for coronary angiography in the Tehran Heart Center between January 2006 and March 2007, were enrolled. All the participants recruited in the study gave their informed consent and filled the study questionnaire providing information on a variety of variables relevant to the assessment of demographics, biochemical markers, such as the lipid profile, and coronary risk factors, such as family history of $\mathrm{CAD}$, current smoking, hypertension, and diabetes mellitus.

\section{CAD assessment}

The existence of coronary lesions was confirmed via coronary angiography. Significant coronary stenosis was defined according to the guideline of the American College of Cardiology/American Heart Association (ACC/AHA) as a $50 \%$ or more narrowing of the luminal diameter in one or more major coronary arteries. $\mathrm{CAD}$ was defined as the presence of at least one coronary vessel with significant stenosis [14]. The number of the diseased coronary vessels was also determined, and the severity of CAD was assessed using the Gensini score, which takes into account the geometrical increase in the severity of lesions, cumulative effects of multiple obstructions, significance of their locations, modifying influence of the collaterals, and size and quality of the distal vessels [15].

\section{Measurement of chemical biomarkers}

Two fasting blood specimens were collected from each patient: one specimen contained the EDETA anticoagulant for DNA extraction and the other contained no anticoagulant for the lipid profile assay. Serum total cholesterol, high-density lipoprotein cholesterol (HDL-C), and triglycerides were measured via enzymatic techniques (Pars Azmoon kits accredited by Bioactiva Diagnostica, Germany). The Friedewald formula was used to calculate low-density lipoprotein cholesterol (LDL-C), except when the triglyceride level was greater than $4.52 \mathrm{mmol} / \mathrm{L}$.

\section{Genotyping methodology}

Genomic DNA was isolated via the proteinase K-buffer method. The polymorphism of the gene was analyzed on the basis of polymerase-chain- 
Table 1. Baseline characteristics and clinical data of the study population.

\begin{tabular}{lccc}
\hline Characteristics & Without CAD $(\mathbf{n}=\mathbf{3 2 6})$ & With CAD $(\mathbf{n}=\mathbf{5 9 3})$ & P \\
\hline Male gender & $169(51.8)$ & $438(73.9)$ & $<0.001$ \\
Age [year] & $56.14 / 10.32$ & $59.64 / 10.17$ & 0.001 \\
Body mass index $\left[\mathrm{kg} / \mathrm{m}^{2}\right]$ & $28.06 / 4.93$ & $27.53 / 4.65$ & 0.111 \\
Family history of CAD & $66(20.2)$ & $153(25.8)$ & 0.059 \\
Diabetes mellitus & $69(21.2)$ & $171(28.8)$ & 0.011 \\
Hypertension & $163(50.0)$ & $276(46.5)$ & 0.315 \\
Current smoking & $54(16.6)$ & $147(24.8)$ & $<0.001$ \\
Serum triglyceride & $177.28 / 89.98$ & $180.28 / 101.90$ & 0.787 \\
Serum cholesterol & $185.18 / 41.35$ & $189.72 / 46.65$ & 0.199 \\
Serum HDL & $45.86 / 10.64$ & $41.80 / 10.42$ & $<0.001$ \\
Serum LDL & $105.46 / 38.32$ & $112.87 / 41.25$ & 0.023 \\
\hline
\end{tabular}

CAD — coronary artery disease; HDL — high-density lipoprotein; LDL — low-density lipoprotein

-reaction (PCR) amplification. A PCR RFLP assay was performed to detect factor VII R353Q polymorphism. PCR was performed with a $50 \mu \mathrm{L}$ reaction mixture containing $2 \mu \mathrm{L}$ of DNA, $10 \mu \mathrm{M}$ of each primer, $2.5 \mathrm{mM}$ of each dNTP, $25 \mathrm{mM}$ of $\mathrm{MgCl} 2$, $5 \mathrm{U} / \mu$ of Taq polymerase, and $10 \mathrm{XKCl}$ of buffer (MBI, Fermentas). Amplification was carried out using primers F 5'-GGGAGACTCCCCAAATATCAC-3', and R5'ACGCAGCCTTGGCTTTCTCTC-3'.The digested products were visualized on $3 \%$ agarose gel stained with ethidium bromide.

\section{Statistical analysis}

The sample size was determined at $95 \%$ confidence interval (CI), $10 \%$ precision and $23.0 \%$ and $13.3 \%$ expected prevalence of heterozygote genotype in cases and controls, respectively, from previous study [16], and found to consist of least 910 patients. In this regard, the study power was also determined at $95.6 \%$. The results are reported as mean \pm standard deviation (SD) for the quantitative variables and percentages for the categorical variables. The groups were compared using the Student $t$-test for the continuous variables and the $\chi^{2}$ test (or the Fisher exact test if required) for the categorical variables. This study was done with the power of $90 \%$. A p value $\leq 0.05$ was considered statistically significant. All the statistical analyses were performed using SPSS version 13.0 (SPSS Inc., Chicago, IL, USA) and SAS version 9.1 for Windows (SAS Institute Inc., Cary, NC, USA).

\section{Results}

A comparison of the baseline characteristics and clinical data of the two groups with and without
CAD (Table 1) showed a higher prevalence rate of diabetes mellitus, current smoking, and, to a lesser degree, family history of $\mathrm{CAD}$ in the former group. Also, the serum level of HDL was lower and LDL level was higher in the CAD group. However, no statistically significant difference was revealed between the groups in terms of body mass index, prevalence of hypertension, and serum levels of triglyceride and total cholesterol.

The results demonstrated no significant difference in the distribution of the wild (QQ), heterozygote (RQ), and homozygous mutant (RR) genotypes of factor VII gene in the different subgroups of patients' characteristics (Table 2). On the other hand, the distribution of these genotypes was not associated with the demographics, the presence or absence of $\mathrm{CAD}$ risk factors, or the level of biochemical markers. The frequency of $\mathrm{Q}$ and $\mathrm{R}$ alleles was $74.1 \%$ and $25.9 \%$ in the patients with CAD, and $75.2 \%$ and $24.8 \%$ in those without $\mathrm{CAD}$, respectively; the difference was insignificant $(p=0.625)$. Regarding the association between the alleles of the gene and the severity of CAD (Fig. 1), the frequency of $\mathrm{Q}$ allele in the patients with single-vessel, two-vessel, and three-vessel diseases was $72.8 \%, 71.5 \%$, and $76.4 \%$; the difference was not significant $(\mathrm{p}=0.379)$. With respect to the distribution of different genotypes of the gene according to the severity of CAD (Fig. 2), no relationship was observed between the distribution of the genotypes and the number of diseased coronary vessels. The average of the Gensini score was $43.39 \pm 46.18$ in the patients with QQ genotype, $38.87 \pm 42.89$ in those with QR genotype, and 55.61 \pm 53.80 in the ones with RR genotype, and the difference was not statistically significant $(\mathrm{p}=0.084)$. 
Table 2. Distribution of factor VII genotypes in the different subgroups of the baseline characteristics.

\begin{tabular}{lcccc}
\hline Characteristics & QQ $(\%)$ & RQ (\%) & RR (\%) & P \\
\hline Male gender & $327(64.5)$ & $237(66.8)$ & $43(75.4)$ & 0.239 \\
Age [year] & $58.28 / 10.37$ & $58.67 / 10.46$ & $57.81 / 9.72$ & 0.762 \\
Body mass index $\left[\mathrm{kg} / \mathrm{m}^{2}\right]$ & $27.71 / 4.88$ & $27.72 / 4.71$ & $27.81 / 3.93$ & 0.823 \\
Family history of CAD & $119(23.5)$ & $81(22.8)$ & $19(33.3)$ & 0.215 \\
Diabetes mellitus & $135(26.6)$ & $90(25.4)$ & $15(26.3)$ & 0.915 \\
Hypertension & $240(47.3)$ & $177(49.9)$ & $22(38.6)$ & 0.275 \\
Current smoking & $104(20.6)$ & $84(23.7)$ & $13(22.8)$ & 0.699 \\
Serum triglyceride & $182.86 / 93.58$ & $176.01 / 106.16$ & $166.81 / 77.95$ & 0.199 \\
Serum cholesterol & $190.79 / 45.53$ & $186.10 / 44.53$ & $176.81 / 38.97$ & 0.071 \\
Serum HDL & $43.09 / 10.69$ & $43.58 / 10.69$ & $42.54 / 10.57$ & 0.570 \\
Serum LDL & $111.63 / 40.077$ & $109.11 / 40.33$ & $104.58 / 36.65$ & 0.340 \\
\hline
\end{tabular}

Abbreviations as in Table 1

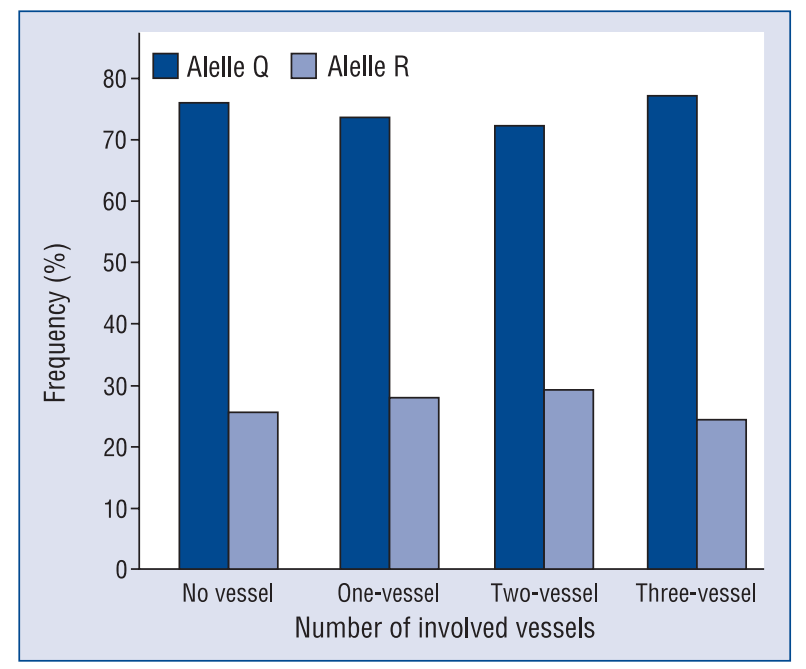

Figure 1. Association between factor VII gene alleles and severity of coronary artery disease.

\section{Discussion}

A comparison between our findings and those previously reported in the literature regarding the association between factor VII R353Q polymorphism and the presence and severity of CAD showed contradictory results (Table 3 ). A review of the literature indicates that the results directly depend on the racial and genetic characteristics of the populations under study and the variety of factors affecting the coding of factor VII gene. Most of the case-control studies revealing a significant association between R353Q polymorphism and $\mathrm{CAD}$, consequences of revascularization, or post-procedural ischemic events were performed on Indian or Indian-Asian populations, while the

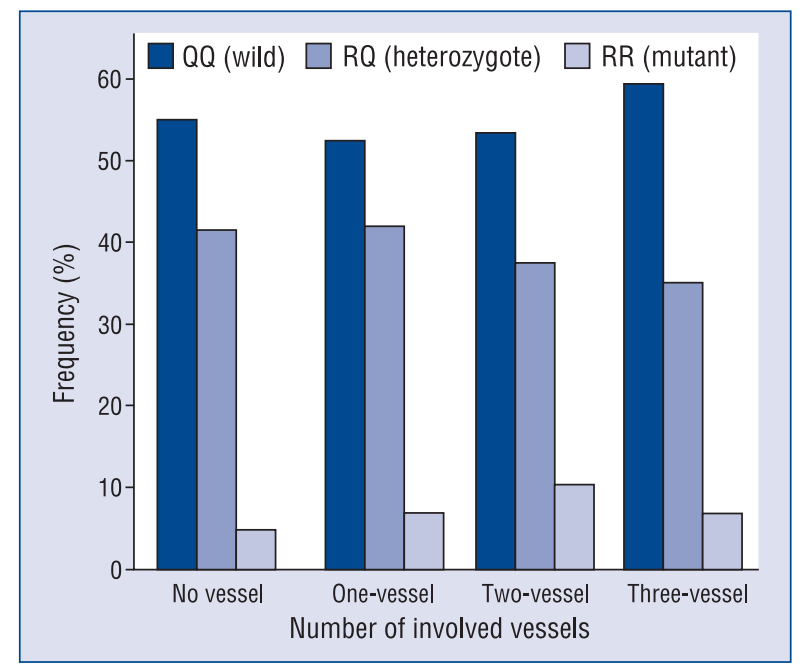

Figure 2. Association between factor VII genotypes and severity of coronary artery disease.

studies carried out on Turkish or European populations obtained opposite results, which might justify the impact of population-based characteristics on the observed differences in the results. In a meta-analysis by Mo et al. [7] on the association between polymorphisms in the coagulation factor VII gene and CAD risk in different ethnicities, it was indicated that $\mathrm{R} 353 \mathrm{Q}$ polymorphism showed a trend for association with CAD only in East Asians. In the 36 retrieved studies in their analysis, the pooled frequency of $\mathrm{Q}$ allele in the $\mathrm{CAD}$ cases and controls was $12.2 \%$ and $12.8 \%$, respectively, and it was found to be $14.2 \%$ and $8.8 \%$ in the control subjects of Caucasian populations and Asians, respectively. Meanwhile, the interactional effects of some underlying CAD risk factors on factor VII 
Table 3. Review of case-control studies on the association between factor VII coronary artery disease (CAD).

\begin{tabular}{|c|c|c|c|}
\hline Author, year & Population & Case-control design & Significance \\
\hline Criado-García, 2011 & European & $\begin{array}{l}720 \text { patients ( } 546 \text { with family history } \\
\text { and } 174 \text { controls) from Spain }\end{array}$ & 0 \\
\hline Sobti, 2010 & Indian & $\begin{array}{l}\text { CHD patients }(n=300) \text { and their } \\
\text { age-matched controls }(n=300)\end{array}$ & 1 \\
\hline Shanker, 2009 & Indian & $\begin{array}{l}139 \text { Indian families with CAD, comprising } \\
222 \text { affected subjects, } 105 \text { unaffected } \\
\text { subjects and } 126 \text { affected sibling pairs }\end{array}$ & 1 \\
\hline Taymaz, 2007 & Turkish & $\begin{array}{l}137 \text { CAD patients with early onset documented } \\
\text { by coronary angiography and } 41 \text { individuals } \\
\text { who had no significant coronary stenosis }\end{array}$ & 0 \\
\hline Quek, 2006 & Asian-Indian & $\begin{array}{c}561 \text { Chinese, } 398 \text { Malays and } 226 \text { Asian Indians } \\
\text { from Singapore }\end{array}$ & 1 \\
\hline Jeffery, 2005 & European & $\begin{array}{l}519 \text { cases, } 400 \text { had no previous MI } \\
\text { or revascularization, including } \\
153 \text { with zero-vessel disease }\end{array}$ & 1 \\
\hline Lu, 2005 & Chinese & $\begin{array}{l}108 \text { elderly patients with CHD and } 120 \text { sex- } \\
\text { and age-matched healthy control subjects }\end{array}$ & 1 \\
\hline Pegoraro, 2005 & Indian Asians & $\begin{array}{c}195 \text { unrelated patients ( } \leq 45 \text { years) } \\
\text { with MI } 107 \text { unaffected siblings ( } 18-45 \text { years) } \\
\text { and } 300 \text { healthy age- and race-matched } \\
\text { control subjects }\end{array}$ & 1 \\
\hline Lindman, 2004 & European & $\begin{array}{l}560 \text { elderly men characterized } \\
\text { as hypercholesterolemic }\end{array}$ & 1 \\
\hline Carew, 2003 & American & 1957 men & 1 \\
\hline Xu, 2003 & Chinese Han & $234 \mathrm{CHD}$ patients and 210 controls & 1 \\
\hline Liu, 2002 & Chinese & $\begin{array}{l}209 \text { male and } 214 \text { female healthy } \\
\text { Chinese individuals }\end{array}$ & 1 \\
\hline Petrovic, 2001 & Slovene & $\begin{array}{l}167 \text { patients with CAD younger than } 55 \text { years } \\
\text { were compared with } 132 \text { healthy subjects }\end{array}$ & 1 \\
\hline Jimenez-Boj, 2000 & Australian & $\begin{array}{l}111 \text { patients with angiographically documented } \\
\text { acute coronary syndromes and } 108 \text { age- } \\
\text { and sex-matched individuals }\end{array}$ & 0 \\
\hline Lievers, 2000 & European & $\begin{array}{l}511 \text { male patients of the Regression } \\
\text { Growth Evaluation Statin Study }\end{array}$ & 0 \\
\hline Song, 2000 & Korean & 139 normal adults and 158 patients with CAD & 0 \\
\hline Hegele, 1997 & $\begin{array}{l}\text { Alberta } \\
\text { Hutterites }\end{array}$ & - & 1 \\
\hline Wang, 1997 & Australian & $\begin{array}{l}545 \text { white Australian patients ( } 388 \text { male } \\
\text { and } 157 \text { female) aged } \leq 65 \text { years }\end{array}$ & 0 \\
\hline Saha, 1994 & Indian & $\begin{array}{l}185 \text { healthy Dravidian Indians } \\
\text { of both sexes ( } 128 \text { men, } 57 \text { women) }\end{array}$ & 1 \\
\hline
\end{tabular}

gene expression and the activity level of its production have been clearly demonstrated. It has been reported that factor VII protein level is directly associated with triglyceride levels in the fasting state so that postprandial increased plasma triglycerides can effectively lead to an increase in factor VII activation [17]. In addition, plasma levels of factor VII are negatively correlated with alcohol consumption $[18,19]$.

Hypertriglyceridemia, as one of the most prominent risk factors, is highly prevalent in our society. On the other hand, alcohol consumption in Iran is far less than that in other communities due to religious edicts. Moreover, the increase in the number of ischemic events through higher levels of activated factor VII is also more pronounced in the presence of other additional CAD risk factors, including smoking, MI events in family, angina pectoris, and high levels of fibrinogen, total cholesterol, and LDL-C, as well as low levels of HDL-C [20]. In a study by Danielsen et al. [21], factor VII concentration and activation was lower 
in patients with previous MI, higher in women and those having previously undergone percutaneous transluminal coronary angioplasty, and also positively related to total cholesterol, duration of $\mathrm{CAD}$, and smoking.

All in all, to explain the association between different polymorphisms in factor VII and CAD severity, it is reasonable to consider the pivotal role of the underlying potential factors, including ethnicity and CAD risk factors.

\section{Conclusions}

According to our findings, it can be concluded that factor VII R353Q polymorphism has no meaningful association with the presence and severity of $\mathrm{CAD}$ in the Iranian population. Given that our center is a referral center for cardiovascular disease in the country, our study population was an appropriate example of our community and the results can be generalized to other parts of the country as well.

\section{Acknowledgements}

This study was supported by the Tehran University of Medical Sciences. We thank the management of the Tehran Heart Center for their critical administrative support and managerial services in carrying out the study and also all researchers for their help and support.

\section{Conflict of interest: none declared}

\section{References}

1. Bratseth V, Pettersen AA, Opstad TB, Arnesen H, Seljeflot I. Markers of hypercoagulability in CAD patients. Effects of single aspirin and clopidogrel treatment. Thromb J, 2012; 10: 12.

2. Rajan L, Moliterno DJ. New anticoagulants in ischemic heart disease. Curr Cardiol Rep, 2012; 14:450-456.

3. Demetz G, Ott I. The Interface between inflammation and coagulation in cardiovascular disease. Int J Inflam, 2012; 2012: 860301.

4. Sobti RC, Maithil N, Thakur H, Sharma Y, Talwar KK. Association of ACE and FACTOR VII gene variability with the risk of coronary heart disease in north Indian population. Mol Cell Biochem, 2010; 341: 87-98.

5. Smith NL, Chen MH, Dehghan A et al. Novel associations of multiple genetic loci with plasma levels of factor VII, factor VIII, and von Willebrand factor: The CHARGE (Cohorts for Heart and Aging Research in Genome Epidemiology) Consortium. Circulation, 2010; 121: 1382-1392.

6. Gutstein DE, Fuster V. Pathophysiology and clinical significance of atherosclerotic plaque rupture. Cardiovasc Res, 1999; 41: 323-333.
7. Mo X, Hao Y, Yang X, Chen S, Lu X, Gu D. Association between polymorphisms in the coagulation factor VII gene and coronary heart disease risk in different ethnicities: A meta-analysis. BMC Med Genet, 2011; 12: 107.

8. Shanker J, Perumal G, Maitra A et al. Genotype-phenotype relationship of F7 R353Q polymorphism and plasma factor VII coagulant activity in Asian Indian families predisposed to coronary artery disease. J Genet, 2009; 88: 291-297.

9. Girelli D, Russo C, Ferraresi P et al. Polymorphisms in the factor VII gene and the risk of myocardial infarction in patients with coronary artery disease. N Engl J Med, 2000; 343: 774-780.

10. Taymaz H, Erarslan S, Oner ET, Alkan T, Ağirbaşli M, Kirdar B. Sequence variations within the genes related to hemostatic imbalance and their impact on coronary artery disease in Turkish population. Thromb Res, 2007; 119: 55-62.

11. Jimenez-Boj E, Schüttrumpf J, Forberg E, Watzke HH, Huber K. The decanucleotide polymorphism in the factor VII promoter predicts factor VII plasma levels but not the risk of acute coronary syndromes. J Thromb Thrombolysis, 2000; 10: 23-28.

12. Lievers KJ, Mennen LI, Rattink AP et al. The 323Ins10 polymorphism for factor VII is not associated with coronary atherosclerosis in symptomatic men. The REGRESS study group. Thromb Res, 2000; 97:275-280.

13. Song J, Yoon YM, Jung HJ, Hong SH, Park H, Kim JQ. Plasminogen activator inhibitor- $14 \mathrm{G} / 5 \mathrm{G}$ promoter polymorphism and coagulation factor VII Arg353 $->$ Gln polymorphism in Korean patients with coronary artery disease. J Korean Med Sci, 2000; 15: $146-152$.

14. Gibbons RJ, Abrams J, Chatterjee K et al. ACC/AHA 2002 guideline update for the management of patients with chronic stable angina: Summary article: a report of the American College of Cardiology/American Heart Association Task Force on Practice Guidelines (Committee on the Management of Patients With Chronic Stable Angina). Circulation, 2003; 107: 159-168.

15. Gensini GG. A more meaningful scoring system for determining the severity of coronary heart disease. Am J Cardiol, 1983; 51: 606.

16. Criado-García J, Fuentes F, Cruz-Teno C et al. R353Q polymorphism in the factor VII gene and cardiovascular risk in heterozygous familial hypercholesterolemia: A case-control study. Lipids Health Dis, 2011; 10: 50.

17. Skartlien AH, Lyberg-Beckmann S, Holme I, Hjermann I, Prydz H. Effect of alteration in triglyceride levels on factor VII-phospholipid complexes in plasma. Arteriosclerosis, 1989; 9: 798-801.

18. Hines LM, Stampfer MJ, Ma J et al. Genetic variation in alcohol dehydrogenase and the beneficial effect of moderate alcohol consumption on myocardial infarction. N Engl J Med, 2001; 344: 549-555.

19. Younis J, Cooper JA, Miller GJ, Humphries SE, Talmud PJ. Genetic variation in alcohol dehydrogenase $1 \mathrm{C}$ and the beneficial effect of alcohol intake on coronary heart disease risk in the Second Northwick Park Heart Study. Atherosclerosis, 2005; 180: 225-232.

20. Junker R, Heinrich J, Schulte H, van de Loo J, Assmann G. Coagulation factor VII and the risk of coronary heart disease in healthy men. Arterioscler Thromb Vasc Biol, 1997; 17: 1539-1544 .

21. Danielsen R, Onundarson PT, Thors H, Vidarsson B, Morrissey JH. Activated and total coagulation factor VII, and fibrinogen in coronary artery disease. Scand Cardiovasc J, 1998; 32: 87-95. 